\title{
Mobile Website Use and Advanced Researchers: Understanding Library \\ Users at a University Marine Sciences Branch Campus
}

\author{
Mary J. Markland, \\ Hannah Gascho Rempel, \\ and Laurie Bridges
}

\begin{abstract}
This exploratory study examined the use of the Oregon State University Libraries website via mobile devices by advanced researchers at an off-campus branch location. Branch campus-affiliated faculty, staff, and graduate students were invited to participate in a survey to determine what their research behaviors are via mobile devices, including frequency of their mobile library website use and the tasks they were attempting to complete. Findings showed that while these advanced researchers do periodically use the library website via mobile devices, mobile devices are not the primary mode of searching for articles and books or for reading scholarly sources. Mobile devices are most frequently used for viewing the library website when these advanced researchers are at home or in transit. Results of this survey will be used to address knowledge gaps around library resources and research tools and to generate more ways to study advanced researchers' use of library services via mobile devices.
\end{abstract}

\section{INTRODUCTION}

As use of mobile devices has expanded in the academic environment, so has the practice of gathering data from multiple sources about what mobile resources are and are not being used. This data informs the design decisions and resource investments libraries make in mobile tools. Web analytics is one tool that allows researchers to discover which devices patrons use to access library webpages. But web analytics data do not show what patrons want to do and what hurdles they face when using the library website via a mobile device. Web analytics also lacks nuance in that it cannot distinguish user characteristics, such as whether users are novice or advanced researchers, which may affect how these users interact with a mobile device. User surveys are another tool for gathering data on mobile behaviors. User surveys help overcome some of the limitations of web analytics data by directly asking users about their perceived research skills and the resources they use on a mobile device.

As is the case at most libraries, Oregon State University Libraries serves a diverse range of users. We were interested in learning whether advanced researchers-particularly advanced researchers who work at a branch campus-use the library's resources differently than main

Mary J. Markland (mary.markland@oregonstate.edu), is Head, Guin Library; Hannah Gascho Rempel (hannah.rempel@oregonstate.edu) is Science Librarian and Coordinator of Graduate Student Success Services; and Laurie Bridges (laurie.bridges@oregonstate.edu) is Instruction and Outreach Librarian, Oregon State University Libraries and Press. 
campus users. We were chiefly interested in these advanced researchers because of the mobile nature of their work. They are graduate students and faculty in the field of marine science who work in a variety of locations, including their offices, labs, and in the field (which can include rivers, lakes, and the ocean). We focused on the use of the library website via mobile devices as one way to determine whether specific library services should be adapted to best meet the needs of this targeted user community.

Oregon State University (OSU) is Oregon's land-grant university; its home campus is in Corvallis, Oregon. Hatfield Marine Science Center (HMSC) in Newport is a branch campus that includes a branch library. Guin Library at HMSC serves OSU students and faculty from across the OSU colleges along with the co-located federal and state agencies of the National Oceanic and Atmospheric Administration (NOAA), US Fish and Wildlife Service, Environmental Protection Agency (EPA), United States Geological Survey (USGS), United States Department of Agriculture (USDA), and the Oregon Department of Fish and Wildlife. The Guin Library is in Newport, which is forty-five miles from the main campus. Like many other branch libraries, Guin Library was established at a time when providing a print collection close to where researchers and students work was paramount, but today it must adapt its services to meet the changing information needs of its user base.

Branch libraries are typically designed to serve a clientele or subject area, which can create a different institutional culture from the main library. Guin Library serves advanced undergraduates, graduate students, and scientific researchers. HMSC's distance from Corvallis, the small size of the researcher community, and the shared focus on a research area-marine sciences-create a distinct culture. While Guin Library is often referred to as the "heart of HMSC," the number of in-person library users is decreasing. This decline is not unexpected as numerous studies have shown that faculty and graduate students have fewer needs that require an in-person trip to the library. ${ }^{1}$ Studies have also shown that faculty and graduate students can be unaware of the services and resources that libraries provide, thereby continuing the cycle of underuse. ${ }^{2}$

To learn more about the needs of HMSC's advanced researchers, this exploratory study examined their research behaviors via mobile devices. The goals of this study were to

- determine if and with what frequency advanced researchers at HMSC use the OSU Libraries website via mobile devices;

- gather a list of tasks advanced users attempt to accomplish when they visit the OSU Libraries website on a mobile device; and

- determine whether the mobile behaviors of these advanced researchers are different from those of researchers from the main OSU campus (including undergraduate students), and if so, whether these differences warrant alternative modes of design or service delivery. 


\section{LITERATURE REVIEW}

The conversation about how best to design mobile library websites has shifted over the past decade. Early in the mobile-adoption process some libraries focused on creating special websites or apps that worked with mobile devices. ${ }^{3}$ While libraries globally might still be creating mobilespecific websites and apps, ${ }^{4}$ US libraries are trending toward responsively designed websites as a more user-friendly option and a simpler solution for most libraries with limited staff and budgets. ${ }^{5}$ Most of the literature on mobile-device use in higher education is focused on undergraduates across a wide range of majors who are using a standard academic library. ${ }^{6}$ To help provide context for how libraries have designed their websites for mobile users, some of those specific findings will be shared later. But because our study focused on graduate students and faculty in a sciencefocused branch library, we will begin with a discussion of what is known about more advanced researchers' use of library services and their mobile-device habits.

Several themes emerged from the literature on graduate students' relationships with libraries. In an ironic twist, faculty think graduate students are being assisted by the library while librarians think faculty are providing graduate students with the help they need to be successful. ${ }^{7}$ This results in many graduate students end up using their library's resources in an entirely disintermediated way. Graduate students, especially those in the sciences, visit the physical library less often and use online resources more than undergraduate students. ${ }^{8}$ Most graduate students start their research process with assistance from academic staff, such as advisors and committee members, ${ }^{9}$ and are unaware of many library services and resources. ${ }^{10}$ As frequent virtual-library users who receive little guidance on how to use the library's tools, graduate students need a library website that is clear in scope and purpose, offers help, and has targeted services. ${ }^{11}$

Compared to reports on undergraduate use of mobile devices to access their library's website, relatively few studies have focused on graduate-student or faculty mobile behaviors. A recent survey of Japanese Library and Information Science (LIS) students compared and undergraduate graduate students' usage of mobile devices to access library services and found slight differences. However, both groups reported accessing libraries as last on their list of preferred smartphone uses. ${ }^{12}$ Aharony examined the mobile use behaviors of Israeli LIS graduate students and found approximately half of these graduate students used smartphones and perceived them to be useful and easy tools for use in their everyday life, and could transfer those habits to library searching behaviors. ${ }^{13}$ When looking specifically at how patrons use library services via a mobile device, Rempel and Bridges found the top reason graduate students at their main campus used the OSU Libraries website via mobile devices was to find information on library hours, followed by finding a book and researching a topic. ${ }^{14}$ Barnett-Ellis and Vann surveyed their small university and found that both undergraduate and graduate students were more than twice as likely to use mobile devices as are their faculty and staff; a majority of students also indicated they were likely to use mobile devices to conduct research. ${ }^{15}$ Finally, survey results showed graduate students in Hofstra University's College of Education reported accessing library materials via a mobile device twice as often as other student groups. In addition, these graduate students reported being comfortable 
reading articles up to five pages long on their mobile devices. Graduate students were also more likely to be at home when using their mobile device to access the library, a finding the authors attributed to education graduate students frequently being employed as full-time teachers. ${ }^{16}$

Research on how faculty members use library resources characterizes a population that is confident in their literature-searching skills, prefers to search on their own, and has little direct contact with the library. ${ }^{17}$ Faculty researchers highly value convenience; 18 they rely primarily on electronic access to journal articles but prefer print access to monographs. ${ }^{19}$ Faculty tend to be self-trained at using search tools, such as PubMed or other online databases, and therefore are not always aware of the more in-depth functionality of these tools. ${ }^{20}$

In contrast to graduate students, Rempel and Bridges found that faculty using the library website via mobile devices were less interested in information about the physical library, such as library hours, and were more likely to be researching a topic. ${ }^{21}$ Medical faculty are one of the few faculty groups whose mobile-research behaviors have been specifically examined. A survey administered by Bushhousen et al. at a medical university revealed that a third of respondents used mobile apps for research-related activities. ${ }^{22}$ Findings by Boruff and Storie indicate that one of the biggest barriers to mobile use in health-related academic settings was wireless access. ${ }^{23}$ Thus apps that did not require the user to be connected to the internet were highly desired. Faculty and graduate students in health-related academic settings saw a role for the library in advocating for better wireless infrastructure, providing access to a targeted set of heavily used resources, and providing online guides or in-person tutorials on mobile apps or procedures specific to their institution. ${ }^{24}$

According to the literature, most design decisions for library mobile sites have been made on the basis of information collected about undergraduate students' behavior at main-branch campuses. To help inform our understanding of how recent decisions have been made, the remainder of the literature review focuses on what is known about undergraduate students' mobile behavior. Undergraduate students are very comfortable using mobile technologies and perceive themselves to be skilled with these devices. According to the 2015 EDUCAUSE Center for Research and Analysis' (ECAR) study of undergraduate students and information technology, most undergraduate students consider themselves sophisticated technology users who are engaged with information technologies. ${ }^{25}$ Undergraduate students mainly use their smartphones for nonclass activities. But students indicate they could be more effective technology users if they were more skilled at tools such as the learning management system, online collaboration tools, e-books, or laptops and smartphones in class. Of interest to libraries is the ECAR participants' top area of reported interest, "search tools to find reference or other information online for class work." 26

However, when a mobile library site is in place, usage rates have been found to be lower than anticipated. In a study of undergraduate science students, Salisbury et al. found only 2 percent of respondents reported using their cell phones to access library databases or the library's catalog every hour or daily, despite 66 percent of the students browsing the internet using their mobile 
phone hourly or daily. Salisbury et al. speculated that users need to be told about mobileoptimized library resources if libraries want to increase usage. ${ }^{27}$

Rempel and Bridges used a pop-up interrupt survey while users were accessing the OSU Libraries mobile site. ${ }^{28}$ This approach allowed a larger cross-section of library users to be surveyed. It also reduced memory errors by capturing their activities in real time. Activities that had been included in the mobile site because of their perceived usefulness in a mobile environment, such as directions, asking a librarian a question, and the coffee shop webcam, were rarely cited as a reason for visiting the mobile site.

The OSU Libraries branch at HMSC is entering a new era. A Marine Studies Initiative will result in the building of a new multidisciplinary research campus at HMSC that aims to serve five hundred undergraduate students. The change in demographics and the increase in students who will need to be served has prompted Guin Library staff to explore how the current population of advanced researchers interact with library resources. In addition, examining the ways undergraduate students at the main campus use these tools will help with planning for the upcoming changes in the user community.

\section{METHODS}

This study used an online Qualtrics survey to gather information about how frequently advanced researchers (graduate students, faculty, and affiliated scientists at a branch library for marine science) use the OSU Libraries website via mobile devices, what they search for, and other ways they use mobile devices to support their research behaviors.

A recruitment email with a link to the survey was sent to three discussion lists used by HMSC community in Spring 2016. The survey was available for four weeks, and a reminder email was sent one week before the survey closed. The invitation email included a link to an informedconsent document. Once the consent document had been reviewed, users were taken to the survey via a second link. Respondents could provide an email address to receive a three-dollar coffee card for participating in the study, but their email address was recorded in a separate survey location to preserve their anonymity. The invitation email indicated that this survey was about using the website via a mobile device, and the first survey question asked users if they had ever accessed the library website on a mobile device. If they answered "no," they were immediately taken to the end of the survey and were not recorded as a participant in the study.

A similar survey was conducted with users from OSU's main campus in 2012-13 and again in 2015. The results from 2012-13 have been published previously, ${ }^{29}$ but the results from 2015 have not. While the focus of the present study is on the mobile behaviors of advanced researchers in the HMSC community, data from the 2015 main-campus study is used to provide a comparison to the broader OSU community. OSU main-campus respondents in 2015 and HMSC participants in 2016 both answered closed- and open-ended questions that explored participants' general mobiledevice behaviors and behaviors specific to using the OSU Libraries website via mobile devices. 
However, the HMSC survey also asked questions about behaviors related to using the OSU (nonlibrary) website via a mobile device and participants' mobile scholarly reading and writing behaviors. The survey concluded with several demographic questions. The survey data was analyzed using Qualtrics' cross-tab functionality and Microsoft Excel to observe trends and potential differences between user groups. Open-ended responses were examined for common themes.

Twenty-three members of the HMSC community completed the survey, whereas one hundred participants responded to the 2015 main campus survey. Participation in the 2015 survey was capped at one hundred respondents because limited incentives were available. The participation difference between the two surveys reflects several differences between the two sampled communities. The most obvious difference is size. The OSU community comprises more than thirty-six thousand students, faculty, and staff; the HMSC community is approximately five hundred students, researchers, and faculty - some of whom are also included as part of the larger OSU community. The second factor influencing response rates relates to the difference in size between the two communities, but is more striking in the HMSC community: the survey relied on a self-selected group of users who indicated they had a history using the library website via a mobile device. Therefore, it is not possible to estimate the population size of mobile-device library-website users specific to the branch library or the main campus library. This limitation means that the results from this study cannot be used to generalize findings to all users who visit a library website via mobile devices; instead the results are intended to present a case that other libraries may compare with behaviors observed on their own campuses. Sharing the behaviors of advanced researchers at a branch campus is particularly valuable as this population has historically been understudied.

\section{RESULTS AND DISCUSSION}

\section{Participant Demographics and Devices Used}

Of the twenty-three respondents to the HMSC mobile behaviors survey, 13 (62 percent) were graduate students, 7 (34 percent) were faculty (this category includes faculty researchers and courtesy faculty), and one respondent was an NOAA employee. Two participants declined to declare their affiliation. Of the 97 respondents to the 2015 OSU main-campus survey who shared their affiliation, 16 (16 percent) were graduate students, 5 ( 5 percent) were faculty members, and 69 (71 percent) were undergraduates.

Respondents varied in the types of mobile devices they used when doing library research. Smartphones were used by 78 percent (18 respondents) and 22 percent ( 5 respondents) used a tablet. Apple (15 respondents) was the most common device brand used, although six of the respondents used an Android phone or tablet. Compared to the general population's device ownership, these respondents are more likely to own Apple devices, but the two major device types owned (Apple and Android) match market trends. ${ }^{30}$ 


\section{Frequency of Library Site Use on Mobile Devices}

Most of the HMSC respondents are infrequent users of the library website via mobile devices: 50 percent (11 respondents) did so less than once a month; 41 percent ( 9 respondents) did so at least once a month; and 9 percent ( 2 respondents) did so at least once a week. The low level of library website usage via mobile devices was especially notable as this population reports being heavy users of the library website via laptops or desktop computers, with 82 percent (18 respondents) visiting the library website via those tools at least once a week.

Researchers at HMSC used the library website via mobile devices much less often than the 2015 main-campus respondents (undergraduates, graduate students, and faculty). No HMSC respondents visited the mobile site daily compared to 10 percent of main-campus users, and only 9 percent of HMSC respondents visited weekly compared to 28 percent of main-campus users (see Figure 1).

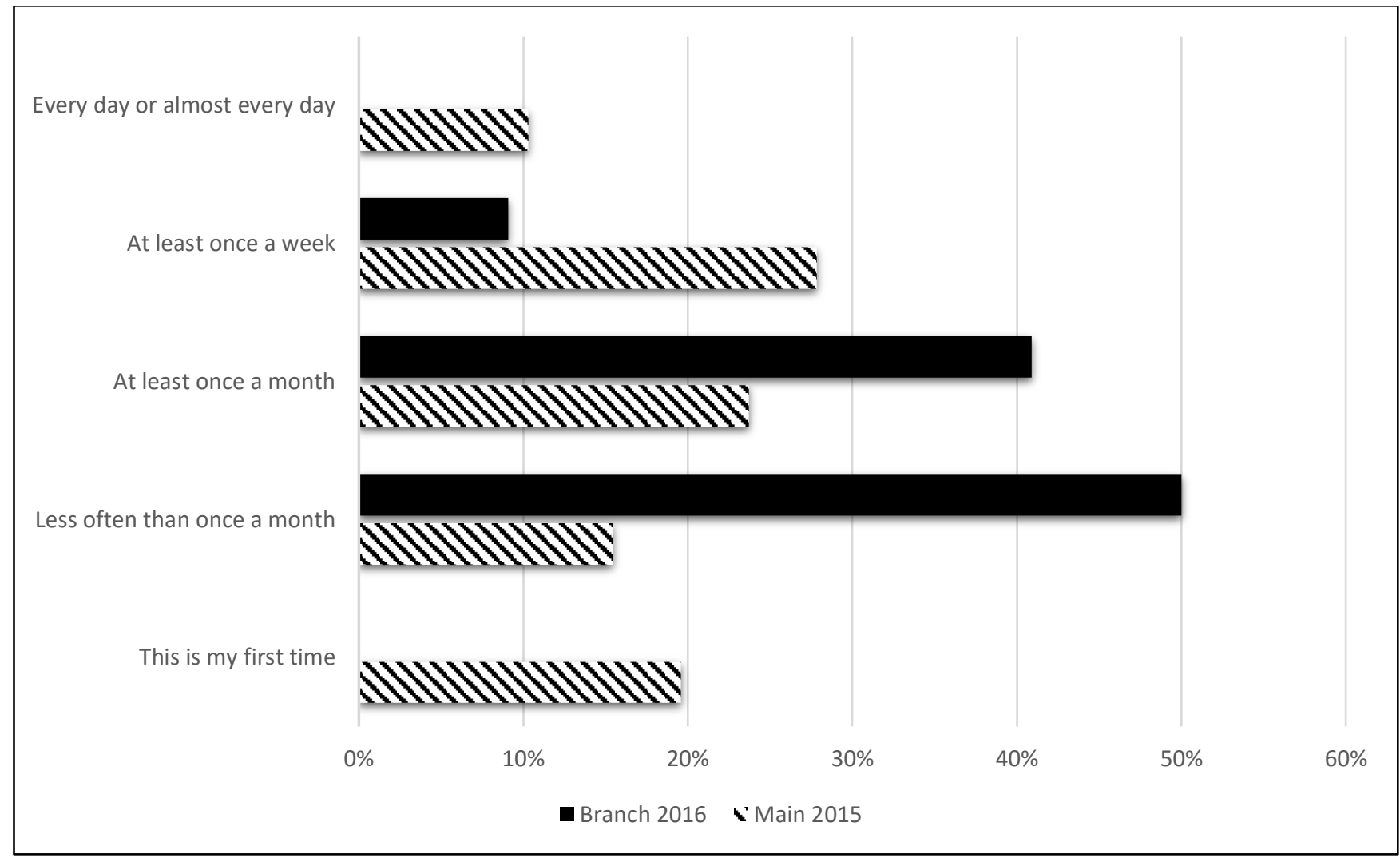

Figure 1. 2016 HMSC participants vs. 2015 OSU main-campus participants reported frequency of library website visits via a mobile device by percent of responses.

While HMSC advanced researchers share some mobile behaviors with main-campus students, this exploratory study demonstrates they do not use the library website via mobile devices as frequently. Some possible reasons for this are researchers rarely spend time coming and going to and from classes and therefore do not have small gaps of time to fill throughout their day. Instead, their daily schedule involves being in the field or in the lab collecting and analyzing data. 
Alternatively, they are frequently involved in writing-intensive projects such as drafting journal articles or grant proposals. They carve out specific periods to do research and do not appear to be filling time with short bursts of literature searching. They can work on laptops and do not need to multitask on a phone or tablet between classes or in other situations. Mobile-device ownership among HMSC graduate students might also be limited because of personal budgets that do not allow for owning multiple mobile devices or for having the most recent model. In addition, this group of scientists may not be on the front edge of personal technologies, especially compared to medical researchers, because few mobile apps are designed specifically for the research needs of marine scientists.

\section{Where Researchers Are When Using Mobile Devices for Library Tasks}

Because mobile devices facilitate connecting to resources from many locations, and because advanced researchers conduct research in a range of settings -including the field, the office, and home-we asked respondents where they were most likely to use the library website via a mobile device. Thirty-two percent were most likely to be at home, 27 percent in transit; 18 percent at work; and 9 percent in the field. The popularity of using the library website via mobile devices while in transit was somewhat unexpected, but perhaps should not have been because many people try to maximize their travel time by multitasking on mobile devices. The distance from the main campus might explain this finding because a local bus service provides an easy way to travel to and from the main campus, and the hour-long trip would provide opportunities for multitasking via a mobile device.

Relatively few respondents used mobile devices to access the library website while at work. Previous studies show that a lack of reliable campus wireless internet access can affect students' ability to use mobile technology. ${ }^{31}$ HMSC also struggles to provide consistent wireless access, and signals are spotty in many areas of our campus. Despite signal boosters in Guin Library, wireless access is still limited at times. In addition, cell phone service is equally spotty both at HMSC and up and down the coast of Oregon. It is much less frustrating to work on a device that has a wired connection to the internet while at HMSC. These respondents did use mobile devices while at home, which might indicate they had a better wireless signal there. Alternatively, working from home on a mobile device might indicate that they compartmentalize their library-research time as an activity to do at home instead of in the office.

Researchers used their mobile devices to access the library while in the field less than originally expected, but upon further reflection, it made sense that researchers would be less likely to use library resources during periods of data collection for oceanic or other water-based research projects because of their focused involvement during that stage. The water-based research also increases the risk of losing mobile devices.

\section{Library Resources Accessed via Mobile Devices}


To learn more about how these respondents used the library website, we asked them to choose what they were searching for from a list of options. Respondents could choose as many options as applied to their searching behaviors. HMSC respondents' primary reason for visiting the library's site via a mobile device was to find a specific source: 68 percent looked for an article, 45 percent for a journal, 36 percent for a book, and 14 percent for a thesis. Many of the HMSC respondents also looked for procedural or library-specific information: 36 percent looked for hours, 32 percent for My Account information, 18 percent for interlibrary loan, 14 percent for contact information, 9 percent for how to borrow and request books, 9 percent for workshop information, and 9 percent for Oregon estuaries bibliographies-a unique resource provided by the HMSC library. Fifty-five percent of searches were for a specific source and 43 percent were for procedural or libraryspecific information. Notably missing from this list were respondents who reported searching via their mobile device for directions to the library.

Compared to the 2015 OSU Libraries main-campus survey respondents, HMSC respondents were much more likely to visit the library website via a mobile device to look for an article (68 percent vs. 37 percent), find a journal (45 percent vs. 23 percent), access My Account information (32 percent vs. 7 percent), use interlibrary loan (18 percent vs. 5 percent), or find contact information (14 percent vs. 1 percent). However, unlike HMSC participants, who do not have access to course reserves at the branch library, 7 percent of OSU main-campus respondents used their mobile devices to find course reserves on the library website. See Figure 2.

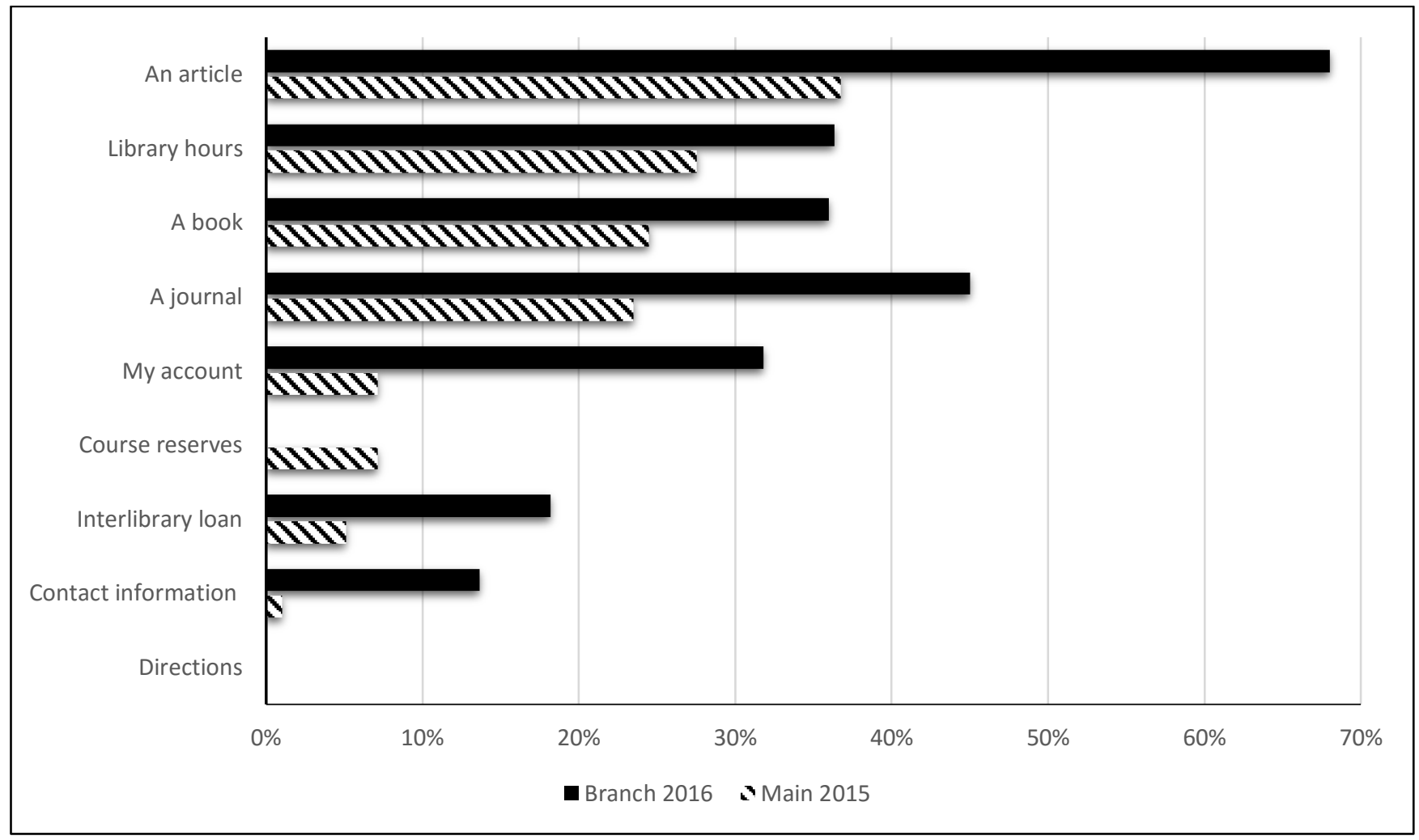


Figure 2. 2016 HMSC vs. 2015 OSU main-campus participants reported searches while visiting the library website via a mobile device by percent of responses.

It is possible that HMSC users with different affiliations might use the library site via a mobile device differently. These exploratory findings show that graduate students used the greatest variety of content via mobile devices. Graduate students as a group reported using 11 of the 14 provided content choices via a mobile device while faculty reported using 8 of the 14 . Graduate students were the largest group (62 percent of respondents), which might explain why as a group they searched for more types of content via mobile devices. Interestingly, faculty members and faculty researchers reported looking for a thesis via a mobile device, but no graduate students did. Perhaps these graduate students had not yet learned about the usefulness of referencing past theses as a starting point for their own thesis writing. Or perhaps they were only familiar with searching for journal articles on a topic. In contrast, faculty members might have been searching for specific theses for which they had provided advising or mentoring support.

To help us make decisions about how to best direct users to library content via mobile devices, we asked respondents to indicate their searching behaviors and preferences. Of the 16 HMSC respondents who answered this question, 12 (75 percent) used our web-scale discovery search box via mobile devices; 4 ( 25 percent) reported that they did. Presumably these latter searchers were navigating to another database to find their sources. Of 16 respondents, only 6 (38 percent) indicated that they looked for a specific library database (as opposed to the discovery tool) when using a mobile device. Those respondents who were looking for a database tended to be looking for the Web of Science database, which makes sense for their field of study. When conducting searches for sources on their mobile devices, HMSC respondents employed a variety of search strategies: the 12 respondents who replied used a combination of author (75 percent), journal title (67 percent, keyword ( 67 percent), and book title (50 percent) searches when starting at the mobile version of the discovery tool.

When asked about their preferred way to find sources, a majority of HMSC respondents reported that they tended to prefer a combination of searching and menu navigation while using the library website from mobile devices, while the remainder were evenly divided between preferring menudriven and search-driven discovery. While OSU Libraries does not currently provide links to any specific apps for source discovery, such as PubMed Mobile or JSTOR Browser, 13 (62 percent) of the HMSC respondents indicated they would be somewhat or very likely to use an app to access and use library services. This finding connects to the issue of reliable wireless access. Medical graduate students had a wider array of apps available to them, but the primary reason they wanted to use these apps was because they provided a better searching experience in hospitals that had intermittent wireless access - an experience to which researchers at HMSC could relate. ${ }^{32}$

\section{University Website Use Behaviors on Mobile Devices}

To help situate respondents' library use behaviors on mobile devices in comparison to the way they use other academic resources on mobile devices, we asked HMSC respondents to describe 
their visits to resources on the OSU (nonlibrary) website via mobile devices. Compared to their use of the library site on a mobile device, respondents' use of university services was higher: 43 percent ( 9 respondents) visited the university's website via a mobile device at least once a week compared to only 9 percent ( 2 respondents) who visited the library site with that frequency. This makes sense because of the integral function many of these university services play in most university employees' regular workflow. Respondents indicated visiting key university sites including MyOSU (a portal webpage, visited by 60 percent of respondents), the HMSC webpage (55 percent), Canvas (the university's learning management system, visited by 50 percent of respondents), and webmail (45 percent). See Figure 3.

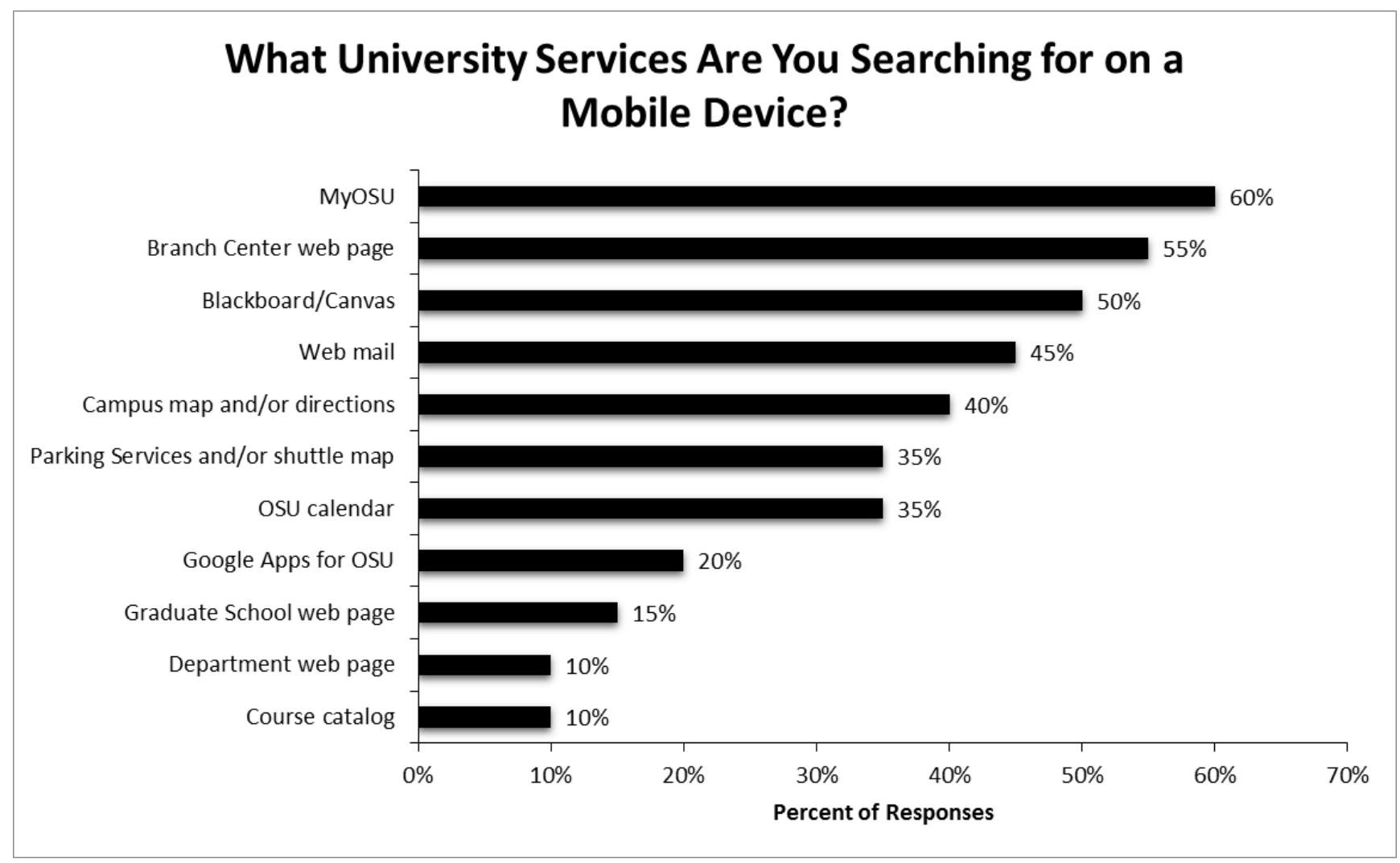

Figure 3. University webpages HMSC respondents access on a mobile device by percent of responses.

University resources such as campus maps, parking locations, and the graduate school website were frequently used by this population. The use of the first two makes sense as HMSC users are located off-site and need to use maps and parking guidance when they visit the main campus. The use of the graduate school website makes sense because the respondents were primarily graduate students and graduate school guidelines are a necessary source of information. Interestingly, our advanced users are similar to undergraduates in that they primarily read email, information from social networking sites, and news on their mobile devices. ${ }^{33}$

Other Research Behaviors on Mobile Devices 
We wanted to know what other research-related behaviors the HMSC respondents are engaged in via mobile devices to determine if there might be additional ways to support researchers' workflows. We specifically asked about respondents' reading, writing, and note-taking behaviors to learn how well these respondents have integrated them with their mobile usage behaviors. All respondents reported reading on their mobile device (see Figure 4). Email represented the most common reading activity (95 percent), followed by "quick reading" activities, such as reading social networking posts (81 percent), current news (81 percent), and blog posts (62 percent). Smaller numbers used their mobile devices for academic or long-form reading, such as reading scholarly articles (33 percent) or books (19 percent). Of those respondents who read articles and books on their mobile devices, only respondents highlighted or took notes using their mobile device. Seven respondents used a citation manager on their mobile device: three used EndNote, one used Mendeley, one used Pages, and one used Zotero. One respondent used Evernote on their mobile device, and one advanced user reported using specific data and database management software, websites, and apps related to their projects. More advanced and interactive mobilereading features, such as online spatial landmarks, might be needed before reading scholarly articles on mobile devices becomes more common. ${ }^{34}$

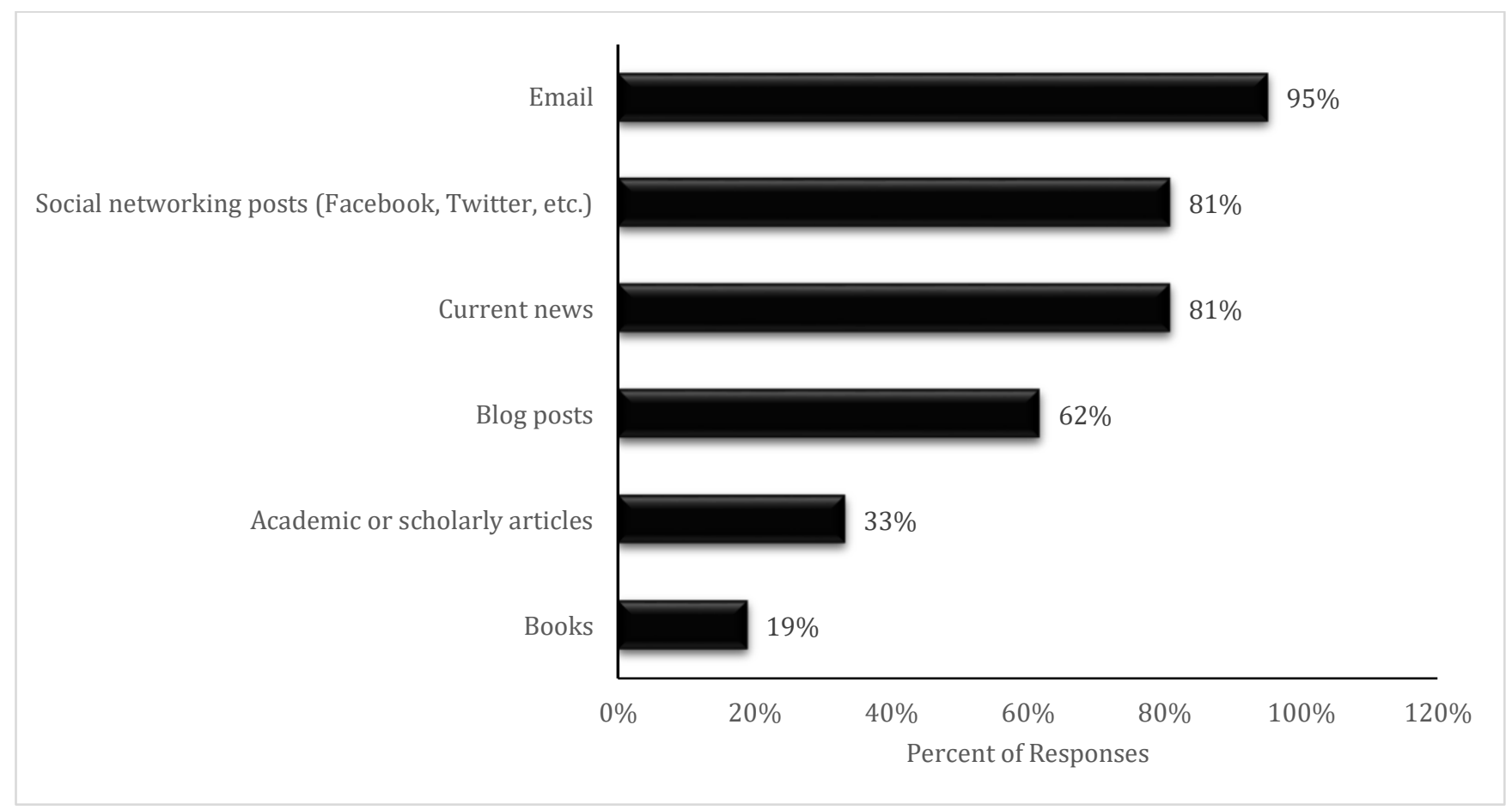

Figure 4. What HMSC respondents reported reading on a mobile device by percent of responses.

\section{LIMITATIONS}

This exploratory study had several limitations, most of which reflect the nature of doing research with a small population at a branch campus. This study had a small sample size, which limited observations of this population; however, future studies could use research techniques such as interviews or ethnographic studies to gather deep qualitative information about mobile-use 
behaviors in this population. A second limitation was that previous studies of the OSU Libraries mobile website used Google Analytics to compare survey results with what users were actually doing on the library website. Unfortunately, this was not possible for this study. Because of how HMSC's network was set up, anyone at HMSC using the OSU internet connections is assigned an IP address that shows a Corvallis, Oregon, location rather than a Newport, Oregon, location, which rendered parsing HMSC-specific users in Google Analytics impossible. The research behaviors of advanced researchers at a branch campus has not been well-examined; despite its limitations, this study provides beneficial insights into the behaviors of this user population.

\section{CONCLUSION}

Focusing on how advanced researchers at a branch campus use mobile devices while accessing library and other campus information provides a snapshot of key trends among this user group. These exploratory findings show that these advanced researchers are infrequent users of library resources via mobile devices and, contrary to our initial expectations, are not using mobile devices as a research resource while conducting field-based research. Findings showed that while these advanced researchers do periodically use the library website via mobile devices, mobile devices are not the primary mode of searching for articles and books or for reading scholarly sources. Mobile devices are most frequently used for viewing the library website when these advanced researchers are at home or in transit.

The results of this survey will be used to address the HMSC knowledge gaps around use of library resources and research tools via mobile devices. Both graduate students and faculty lack awareness of library resources and services and have unsophisticated library research skills. ${ }^{35}$ While the OSU main campus has library workshops for graduate students and faculty, these workshops have been inconsistently duplicated at the Guin Library. Because the people working at HMSC come from such a wide variety of departments across OSU that focus on marine sciences, HMSC has never had a library orientation. The results indicate possible value in devising ways to promote Guin Library's resources and services locally, which could include highlighting the availability of mobile library access. While several participants mentioned using research tools like Evernote, Pages, or Zotero on their mobile devices, most participants did not report enhancing their mobile research experience with these mobile-friendly tools. Workshops specifically modeling how to use mobile-friendly tools and apps such as Dropbox, Evernote, GoodReader, or Browzine could help introduce the benefits of these tools to these advanced researchers.

Because wireless access is even more of a concern for researchers at this branch location than for researchers at the main campus, database-specific apps will be explored to determine if the use of searching apps could help alleviate inconsistent wireless access. If database apps that are appropriate for marine science researchers are available, these will be promoted to this user population.

Future research might involve follow-up interviews or focus groups, ethnographic studies, or interviews, which could expand the knowledge of these researchers' mobile-device behaviors and 
their perceptions of mobile devices. Exploring the technology usage by these advanced researchers in their labs, including electronic lab notebooks or other tools, might be an interesting contrast to their use of mobile devices. In addition, as the HMSC campus grows with the expansion of the Marine Studies Initiative, increasing numbers of undergraduates will use Guin Library. The ECAR 2015 statistics show that current undergraduates own multiple internet-capable devices. ${ }^{36}$ Presumably, these HMSC undergraduates will be likely to follow the trends seen in the ECAR data. Certainly, the plans to expand HMSC's internet and wireless infrastructure will affect all its users.

Our mobile survey gave us insights into how a sample of the HMSC population uses the library's resources and services. These observations will allow Guin Library to expand its services for the HMSC campus. We encourage other librarians to explore their unique user populations when evaluating services and resources.

\section{REFERENCES}

${ }^{1}$ Maria Anna Jankowska, “Identifying University Professors' Information Needs in the Challenging Environment of Information and Communication Technologies," Journal of Academic Librarianship 30, no. 1 (2004): 51-66, https://doi.org/10.1016/i.jal.2003.11.007; Pali U. Kuruppu and Anne Marie Gruber, "Understanding the Information Needs of Academic Scholars in Agricultural and Biological Sciences," Journal of Academic Librarianship 32, no. 6 (2006): 609-23; Lotta Haglund and Per Olsson, "The Impact on University Libraries of Changes in Information Behavior among Academic Researchers: A Multiple Case Study," Journal of Academic Librarianship 34, no. 1 (2008): 52-59, https://doi.org/10.1016/j.acalib.2007.11.010; Nirmala Gunapala, "Meeting the Needs of the 'Invisible University': Identifying Information Needs of Postdoctoral Scholars in the Sciences," Issues in Science and Technology Librarianship, no. 77 (Summer 2014), https://doi.org/10.5062/F4B8563P.

2 Tina Chrzastowski and Lura Joseph, “Surveying Graduate and Professional Students' Perspectives on Library Services, Facilities and Collections at the University of Illinois at UrbanaChampaign: Does Subject Discipline Continue to Influence Library Use?," Issues in Science and Technology Librarianship no. 45 (Winter 2006), https://doi.org/10.5062/F4DZ068I; Kuruppu and Gruber, "Understanding the Information Needs of Academic Scholars in Agricultural and Biological Sciences"; Haglund and Olsson, "The Impact on University Libraries of Changes in Information Behavior Among Academic Researchers."

${ }^{3}$ Ellyssa Kroski, “On the Move with the Mobile Web: Libraries and Mobile Technologies," Library Technology Reports 44, no. 5 (2008): 1-48, https://doi.org/10.5860/ltr.44n5.

4 Paula Torres-Pérez, Eva Méndez-Rodríguez, and Enrique Orduna-Malea, "Mobile Web Adoption in Top Ranked University Libraries: A Preliminary Study," Journal of Academic Librarianship 42, no. 4 (2016): 329-39, https://doi.org/10.1016/j.acalib.2016.05.011.

5 David J. Comeaux, "Web Design Trends in Academic Libraries-A Longitudinal Study," Journal of Web Librarianship 11, no. 1 (2017), 1-15, https://doi.org/10.1080/19322909.2016.1230031; 
Zebulin Evelhoch, "Mobile Web Site Ease of Use: An Analysis of Orbis Cascade Alliance Member Web Sites," Journal of Web Librarianship 10, no. 2 (2016): 101-23, https://doi.org/10.1080/19322909.2016.1167649.

6 Barbara Blummer and Jeffrey M. Kenton, “Academic Libraries' Mobile Initiatives and Research from 2010 to the Present: Identifying Themes in the Literature," in Handbook of Research on Mobile Devices and Applications in Higher Education Settings, ed. Laura Briz-Ponce, Juan JuanesMéndez, and José Francisco García-Peñalvo (Hershey, PA: IGI Global, 2016), 118-39.

7 Jankowska, "Identifying University Professors' Information Needs in the Challenging Environment of Information and Communication Technologies."

${ }^{8}$ Chrzastowski and Joseph, "Surveying Graduate and Professional Students' Perspectives on Library Services, Facilities and Collections at the University of Illinois at Urbana-Champaign."

${ }^{9}$ Carole A. George et al., "Scholarly Use of Information: Graduate Students' Information Seeking Behaviour," Information Research 11, no. 4 (2006), http://www.informationr.net/ir/114/paper272.html.

${ }^{10}$ Kristin Hoffman et al., "Library Research Skills: A Needs Assessment for Graduate Student Workshops," Issues in Science and Technology Librarianship 53 (Winter-Spring 2008), https://doi.org/10.5062/F48P5XFC; Hannah Gascho Rempel and Jeanne Davidson, "Providing Information Literacy Instruction to Graduate Students through Literature Review Workshops," Issues in Science and Technology Librarianship 53 (Winter-Spring 2008), https://doi.org/10.5062/F44X55RG.

${ }^{11}$ Jankowska, "Identifying University Professors' Information Needs in the Challenging Environment of Information and Communication Technologies."

12 Ka Po Lau et al., "Educational Usage of Mobile Devices: Differences Between Postgraduate and Undergraduate Students," Journal of Academic Librarianship 43, no. 3 (May 2017), 201-8, https://doi.org/10.1016/j.acalib.2017.03.004.

${ }^{13}$ Noa Aharony, "Mobile Libraries: Librarians' and Students' Perspectives," College \& Research Libraries 75, no. 2 (2014): 202-17, https://doi.org/10.5860/crl12-415.

${ }^{14}$ Hannah Gashco Rempel and Laurie M. Bridges, "That Was Then, This Is Now: Replacing the Mobile-Optimized Site with Responsive Design," Information Technology and Libraries 32, no. 4 (2013): 8-24, https://doi.org/10.6017/ital.v32i4.4636.

15 Paula Barnett-Ellis and Charlcie Pettway Vann, "The Library Right There in My Hand:

Determining User Needs for Mobile Services at a Medium-Sized Regional University," Southeastern Librarian 62, no. 2 (2014): 10-15. 
16 William T. Caniano and Amy Catalano, "Academic Libraries and Mobile Devices: User and Reader Preferences," Reference Librarian 55, no. 4 (2014), 298-317, https://doi.org/10.1080/02763877.2014.929910.

17 Haglund and Olsson, "The Impact on University Libraries of Changes in Information Behavior Among Academic Researchers."

18 Kuruppu and Gruber, "Understanding the Information Needs of Academic Scholars in Agricultural and Biological Sciences."

${ }^{19}$ Christine Wolff, Alisa B. Rod, and Roger C. Schonfeld, “Ithaka S+R US Faculty Survey 2015," Ithaka S+R, April 4, 2016, http://www.sr.ithaka.org/publications/ithaka-sr-us-faculty-survey2015/.

${ }^{20}$ M. Macedo-Rouet et al., "How Do Scientists Select Articles in the PubMed Database? An Empirical Study of Criteria and Strategies," Revue Européenne de Psychologie Appliquée/European Review of Applied Psychology 62, no. 2 (2012): 63-72.

${ }^{21}$ Rempel and Bridges, "That Was Then, This Is Now."

22 Ellie Bushhousen et al., "Smartphone Use at a University Health Science Center," Medical Reference Services Quarterly 32, no. 1 (2013): 52-72, https://doi.org/10.1080/02763869.2013.749134.

23 Jill T. Boruff and Dale Storie, "Mobile Devices in Medicine: A Survey of How Medical Students, Residents, and Faculty Use Smartphones and Other Mobile Devices to Find Information," Journal of the Medical Library Association 102, no. 1 (2014): 22-30, https://doi.org/10.3163/1536-

$\underline{5050.102 .1 .006}$.

${ }^{24}$ Bushhousen et al., "Smartphone Use at a University Health Science Center"; Boruff and Storie, "Mobile Devices in Medicine."

25 Eden Dahlstrom et al., "ECAR Study of Students and Information Technology, 2015," research report, EDUCAUSE Center for Analysis and Research, 2015, https://library.educause.edu/ /media/files/library/2015/8/ers1510ss.pdf?la=en.

26 Ibid., 24.

27 Lutishoor Salisbury, Jozef Laincz, and Jeremy J. Smith, "Science and Technology Undergraduate Students' Use of the Internet, Cell Phones and Social Networking Sites to Access Library Information," Issues in Science and Technology Librarianship 69 (Spring 2012), https://doi.org/10.5062/F4SB43PD.

${ }^{28}$ Rempel and Bridges, "That Was Then, This Is Now.”

29 Ibid. 
30 “Mobile/Tablet Operating System Market Share," NetMarketShare, March 2017, https://www.netmarketshare.com/operating-system-market-share.aspx?qprid=8\&qpcustomd=1.

31 Boruff and Storie, "Mobile Devices in Medicine"; Patrick Lo et al., "Use of Smartphones by Art and Design Students for Accessing Library Services and Learning," Library Hi Tech 34, no. 2 (2016): 224-38, https://doi.org/10.1108/LHT-02-2016-0015.

32 Boruff and Storie, "Mobile Devices in Medicine."

33 Dahlstrom et al., "ECAR Study of Students and Information Technology, 2015."

34 Caroline Myrberg and Ninna Wiberg, "Screen vs. Paper: What Is the Difference for Reading and Learning?" Insights 28, no. 2 (2015): 49-54, https://doi.org/10.1629/uksg.236.

35 Barnett-Ellis and Vann, "The Library Right There in My Hand”; Haglund and Olsson, "The Impact on University Libraries of Changes in Information Behavior Among Academic Researchers";

Hoffman et al., "Library Research Skills"; Kuruppu and Gruber, "Understanding the Information Needs of Academic Scholars in Agricultural and Biological Sciences"; Lau et al., "Educational Usage of Mobile Devices"; Macedo-Rouet et al., "How Do Scientists Select Articles in the PubMed Database?"

${ }^{36}$ Dahlstrom et al., "ECAR Study of Students and Information Technology, 2015.” 